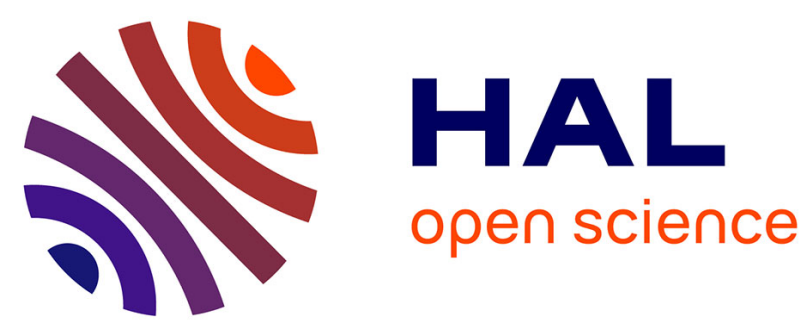

\title{
Numerical investigation of combustion noise: The Entropy Wave Generator
}

César Becerril, Stéphane Moreau, Michael Bauerheim, Laurent Gicquel, Thierry Poinsot

\section{To cite this version:}

César Becerril, Stéphane Moreau, Michael Bauerheim, Laurent Gicquel, Thierry Poinsot. Numerical investigation of combustion noise: The Entropy Wave Generator. 22nd AIAA/CEAS Aeroacoustics Conference, May 2016, Lyon, France. pp.1-18, 10.2514/6.2016-2830 . hal-02154836

\section{HAL Id: hal-02154836 \\ https://hal.science/hal-02154836}

Submitted on 13 Jun 2019

HAL is a multi-disciplinary open access archive for the deposit and dissemination of scientific research documents, whether they are published or not. The documents may come from teaching and research institutions in France or abroad, or from public or private research centers.
L'archive ouverte pluridisciplinaire HAL, est destinée au dépôt et à la diffusion de documents scientifiques de niveau recherche, publiés ou non, émanant des établissements d'enseignement et de recherche français ou étrangers, des laboratoires publics ou privés. 


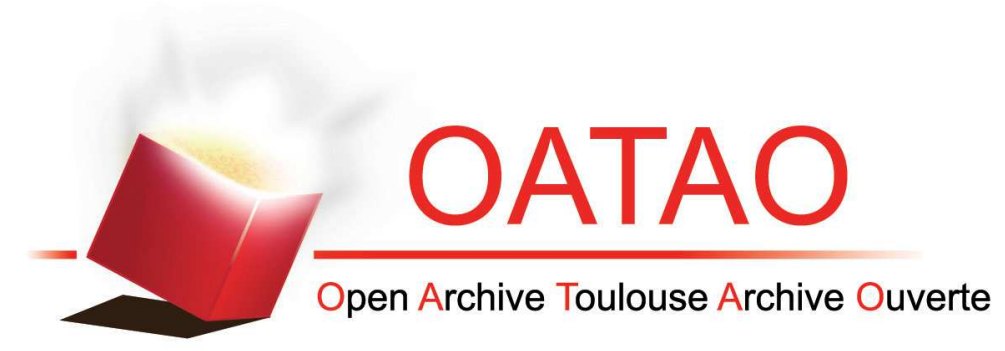

\section{Open Archive Toulouse Archive Ouverte (OATAO)}

OATAO is an open access repository that collects the work of some Toulouse researchers and makes it freely available over the web where possible.

This is an author's version published in: https://oatao.univ-toulouse.fr/20705

Official URL : http://doi.org/10.2514/6.2016-2830

\section{To cite this version :}

Becerril, César and Moreau, Stéphane and Bauerheim, Michael and Gicquel, Laurent and Poinsot, Thierry Numerical investigation of combustion noise: The Entropy Wave Generator. (2016) In: 22nd AIAA/CEAS Aeroacoustics Conference, 30 May 2016 - 1 June 2016 (France).

Any correspondence concerning this service should be sent to the repository administrator: tech-oatao@listes-diff.inp-toulouse.fr 


\title{
Numerical investigation of combustion noise The Entropy Wave Generator
}

\author{
César Becerril * , \\ Stéphane Moreau ${ }^{\dagger}$,Michael Bauerheim ${ }^{\ddagger}$,Laurent Gicquel ${ }^{\S}$,Thierry Poinsot ฯ
}

\section{Nomenclature}

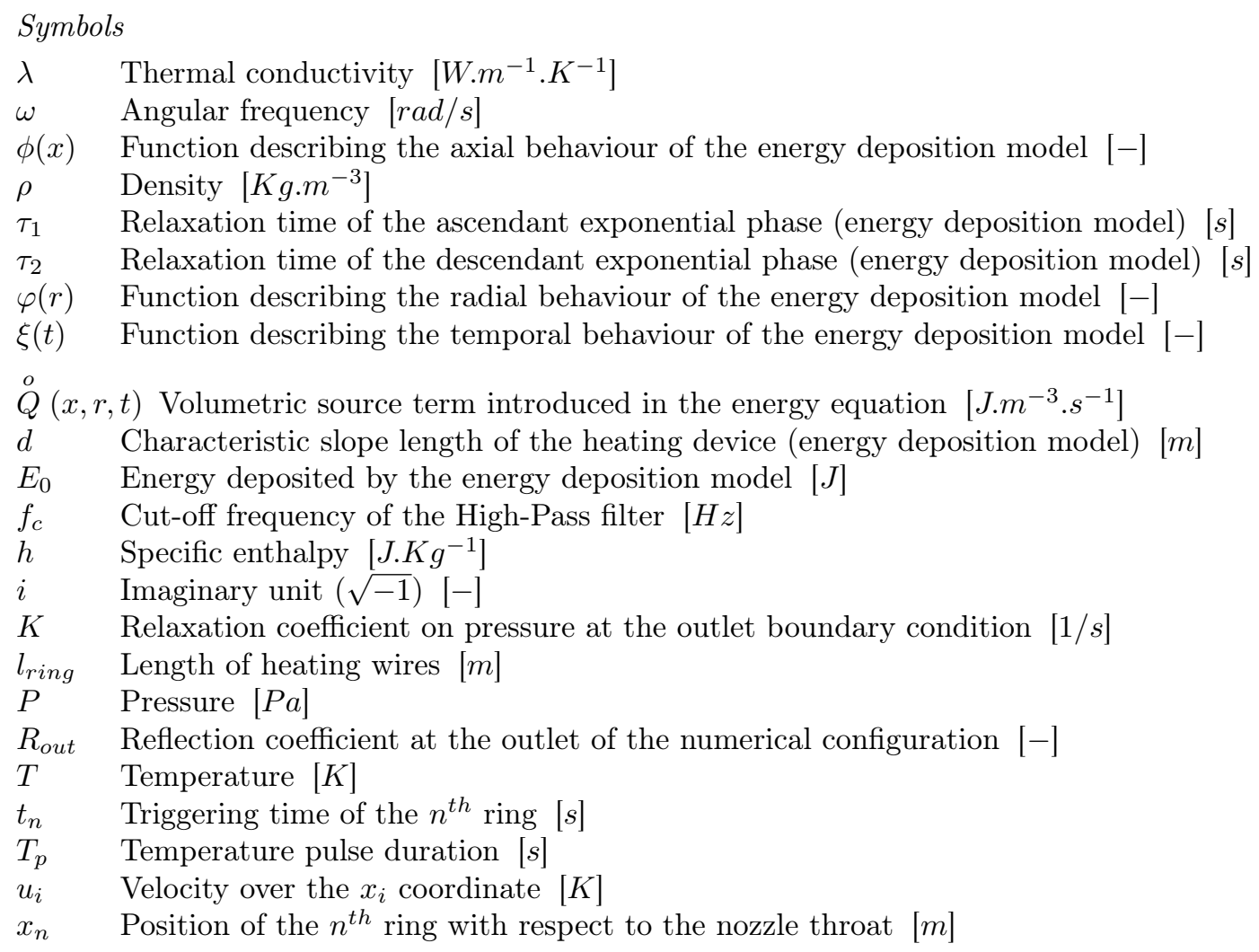

\section{Introduction}

The noise produced by an aero-engine has been reduced drastically in the last few years. Different noise sources have been identified and reduced (jet, fan, turbo-machinery and external aerodynamic noise), all except combustion noise. Combustion noise is caused by fluctuations of heat release. These perturbations produce acoustic and entropy waves that propagate through the turbine stages. Two mechanisms of noise generation can be identified. The first one is called direct noise, where the unsteady fluctuations of heat release produce acoustic waves. The second one is called indirect noise, where the acceleration of hot/cold

\footnotetext{
*PhD Student, CERFACS, becerril@cerfacs.fr

${ }^{\dagger}$ Professor, Mechanical Engineering Department, AIAA Lifetime Member

${ }^{\ddagger}$ Post-doctoral fellow, CERFACS

§Senior Researcher, CERFACS

`Research Director, IMFT
} 
spots and vorticity through the turbine blades generates acoustic waves. The propagation of acoustic waves was first studied by Tsien [1] in a rocket engine within the combustion instability framework. Marble and Candel [2] extended this study to take into account entropy waves and computed the wave transfer functions of a compact nozzle (where the nozzle length is considered small compared with the wavelength of the perturbations). Cumpsty and Marble [3] extended the 1D compact nozzle theory of Marble and Candel to take into account 2D compact stator and rotor blades. Huet and Giauque [4] developed a model to take into account the non linear effects produced by high temperature fluctuations (typically above $10 \%$ of the averaged background temperature) within the compact theory. Nevertheless, work done by Marble and Candel [2] and Moase et al. [5] showed that the modulus of the transfer functions of chocked nozzles changes significantly with frequency and hence the compact theory is no longer valid. Marble and Candel [2] assume that the nozzle has a defined geometry with a linear velocity profile, obtaining for this very specific case an analytical solution in the form of an hyper-geometric differential equation. Moase et al. [5] considered a chocked nozzle where the velocity profile was approached as piecewise-linear and used the solution of Marble and Candel for each interval to obtain the nozzle transfer functions. Stow et al. [6] used an asymptotic analysis to compute a first order correction to the compact hypothesis in the case of a choked nozzle obtaining an effective nozzle length to correct the phase prediction of the reflection coefficient. Goh and Morgans [7] extended this approach to compute the transition coefficient of a nozzle with a choked flow. Finally, Duran and Moreau [8] solved the quasi 1-D linearised Euler Equations (LEE) giving an extension to the compact assumption to the whole frequency domain for all types of nozzle.

The German Aerospace Center (DLR) constructed different test rigs [9-12] to study the acoustics generated by the acceleration of entropy and vorticity waves (indirect noise). The first experimental test ring is the Entropy Wave Generator (EWG, described in section II), which was the first one that showed conclusively the generation of indirect noise that eluded the community for several decades. Different laboratories have already computed the EWG analytically and numerically. A supersonic test case with a shock in the nozzle divergent was computed analytically and numerically by Leyko et al. [13]. The 1-D theory and a compact assumption for the nozzle (i.e. Marble and Candel [2]) was used as analytical approach, and an Euler simulation of a ten degree sector using the AVBP code (Schønfeld and Rudgyard [14]) provided numerical one. A very good agreement between the analytical and numerical methods in comparison with the experiment was found. It shows that for the supersonic case, the compact assumption and the knowledge of the acoustic outlet boundary condition are sufficient to obtain satisfactory results. Duran et al. $[15,16]$ computed a subsonic test case of the EWG using the same approach as Leyko et al., but added to the analytical method the resolution of non zero frequencies by solving the Linearised Euler Equations in the frequency domain. In their study of the EWG subsonic test case, they showed that direct noise is dominant over indirect noise and that for larger Mach numbers in the nozzle, analytical methods overestimate the predicted pressure peak. Muhlbauer et al. [17] computed the supersonic test case by means of URANS method coupled to acoustic boundary conditions obtaining also very good results in comparison with the experiment. Ullrich et al. [18] computed both subsonic and supersonic configurations of the EWG by means of RANS simulations for the unforced flow and a Linerarised Navier-Stokes Equations (LNSE) for the acoustic and entropy forcing. They looked for the acoustic response of an entropy fluctuation and the acoustic scattering behaviour of the nozzle. Finally, in the work of Lourier et al. [19], a new approach to treat the acoustic boundary conditions in time domain (TDIBC) was coupled with a URANS approach to solve the subsonic test case of the EWG configuration. Good results have been found in comparison to the experimental data, maximal and minimal peaks of the pressure response have been well reproduced but still some overestimations of the signal and some time delay remain. Finally, this work claimed that the indirect noise dominates direct noise (which somewhat contradicts previous results by Duran et al. $[15,16])$.

A Large Eddy Simulation of a subsonic operating point (test case number two from Bake et al. [9]) of the EWG is presented in this paper. This study has three goals. The first is to provide a larger database on the generation of indirect noise than the one provided by RANS simulations and analytical models. The second is to determine the dominant noise in the subsonic case (direct or indirect). The third is to understand the reason of the overestimation of the pressure peak noise when the nozzle Mach number increases (i.e. Figure 1). As an explanation to the third phenomenon, Howe [20] suggested firstly that in cases with flow separation in the nozzle diffuser, vortex sound is strongly correlated with entropy noise and can dramatically reduce the overall sound level. Secondly, the strong deformation of the hot slug in the nozzle throat reduces 
the entropy gradients within the front and rear interfaces of the slug generating a decrease in acoustic pressure.

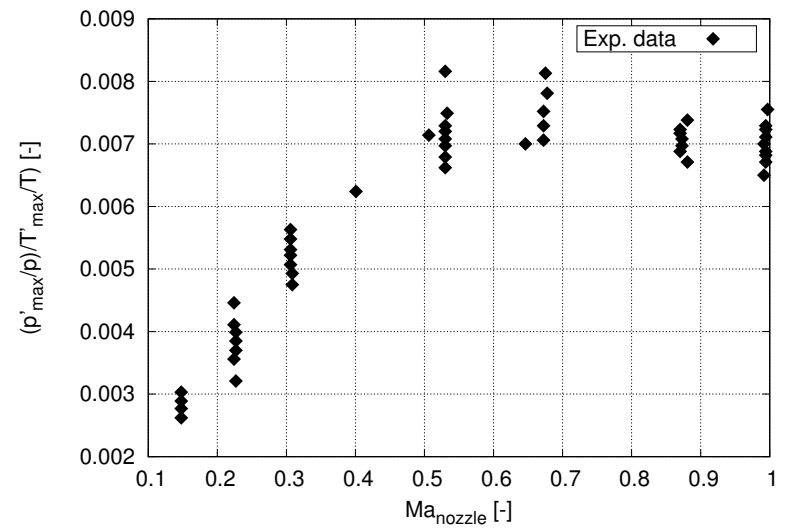

Figure 1: Normalized entropy noise over nozzle Mach number measured at the EWG test rig from Bake et al. [9].

This work is organized as follows. In §II a brief description of the EWG experiment and the operating point considered in this study is presented. In §III several numerical simulations are discussed, from the baseline flow of a subsonic operating point (§III.1) to the entropy forced configuration of the experiment (§III.2). §III.2.1 discusses the model representing the heating device in the simulations and §III.2.2 the influence of the inlet acoustic boundary condition.

\section{The experimental test rig}

The EWG test rig shown in Figure 2 located at the German Aerospace Center (DLR) consists basically on a convergent-divergent nozzle. The flow is supplied through a mass flow controller, enters the set-up into a settling chamber with a honeycomb flow straightener before entering into a straight tube of $30 \mathrm{~mm}$ of diameter and $250 \mathrm{~mm}$ of length. A heating device composed of six heating wire modules is located in the middle of this tube. This device is capable of inducing different entropy wave shapes. After the heating device, the flow enters into the convergent divergent nozzle in which the flow is strongly accelerated. When the entropy wave generated by the heating device goes through the nozzle, it produces the so called indirect noise. Downstream of the nozzle, another tube section with a length of $1020 \mathrm{~mm}$ and a diameter of $40 \mathrm{~mm}$ is placed. In this tube section four wall-flushed microphones (1/4-inch Pressure Microphone Type 40BP from G.R.A.S) are installed to measure the pressure perturbation induced by the acceleration of the entropy wave. It has been found that this kind of probes measures only pressure fluctuations and has a sensibility that can be approached as a first order high-pass filter. The transfer function of the microphones was obtained from the manufacturer and is given if Figure 3.

The reference subsonic case of Bake et al. [9] is considered in this study. The different geometric and flow parameters are summarized in Table 1. A $100 \mathrm{~ms}$ long hot streak is produced by the heating device every second. The temperature fluctuation is measured by a vibrometer and the pressure fluctuations generated by the acceleration of the hot spot are measured by four microphones located in the downstream duct. Positions of the vibrometer and different microphones are: $x_{v i b}=-58 \mathrm{~mm}, x_{m i c 1}=350.5 \mathrm{~mm}, x_{m i c 2}=730.5 \mathrm{~mm}$, $x_{m i c 3}=975.5 \mathrm{~mm}$ and $x_{m i c 4}=1150.5 \mathrm{~mm}$ from the nozzle throat, as shown in Figure 2

\section{Numerical investigation of the subsonic EWG test case $(M=0.7)$}

Leyko et al. [13] pointed out the importance of taking into account the correct value of the downstream reflection coefficient of the EWG configuration. They have shown that the outlet reflection coefficient can be approached as a low pass filter (as done by Selle et al. [21]), with a relaxation parameter $K=160$, Eq.(1). 


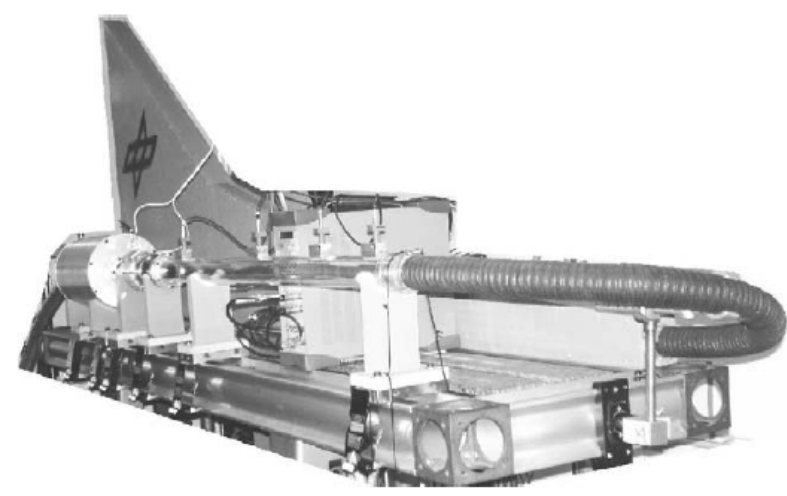

(a) EWG test rig photo

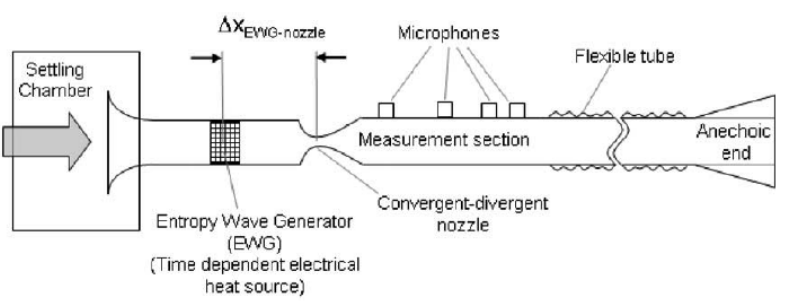

(b) EWG sketch

Figure 2: Entropy Wave Generator test rig configuration.

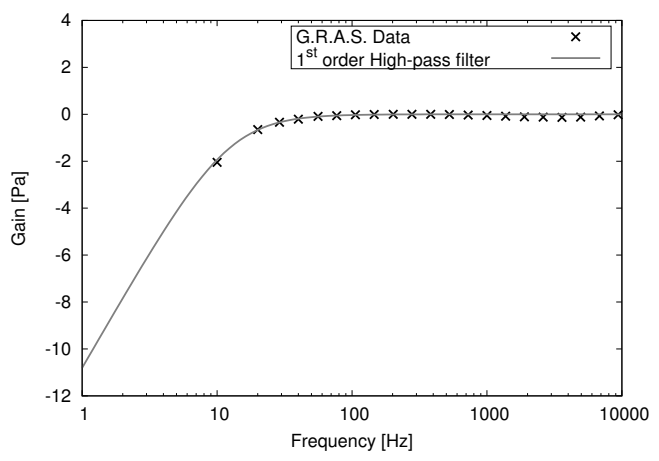

Figure 3: Transfer function of microphone "1/4-inch Pressure Microphone Type 40BP" approached by a first order high-pass filter with cut-off frequency $f_{c}=12 \mathrm{~Hz}$.

\begin{tabular}{|l|c|}
\hline \multicolumn{1}{|c|}{ Parameter } & Value \\
\hline \hline Mass flow rate $(\mathrm{Kg} / \mathrm{h})$ & 37 \\
Nozzle Mach number & 0.7 \\
Ambient pressure $(\mathrm{hPa})$ & 1013 \\
Pulse duration $(\mathrm{ms})$ & 100 \\
Pulse repetition rate $(\mathrm{s})$ & 1 \\
Temperature increase $\Delta \mathrm{T}$ measured $(\mathrm{K})$ & 13.4 \\
Heated wire rings & $1-6$ \\
\hline
\end{tabular}

Table 1: List of parameters of the reference test case 2 .

Nevertheless, the configuration studied by Leyko et al. was a supersonic operating point. Hence, the upstream acoustic boundary condition was irrelevant.

$$
R_{o u t}=-\frac{1}{1+\frac{i \omega}{K}}
$$

Duran et al. [15] computed the subsonic operating point of the EWG with three different approaches, of different complexity and accuracy. First of all, a 2-D axisymmetric numerical simulation resolving the Euler equations was performed. Secondly, an analytical approach using the compact assumption described by Marble and Candel [2] was applied. Finally, the Linearised Euler Equations (LEE) are solved numerically in the frequency domain using the CERFACS in-house code SNOZZLE [16] to evaluate the influence of higher 
frequencies that are not taken into account within the compact approach. These simulations showed that in the subsonic case the upstream impedance now plays a key role, but it has not been measured by Bake et al. Figure 4(a) shows the pressure signals obtained by Duran et al. [15] with these three methods, as well as the experimental results from Bake et al. [9]. Figure 4 reveals that all these methods overestimate the pressure

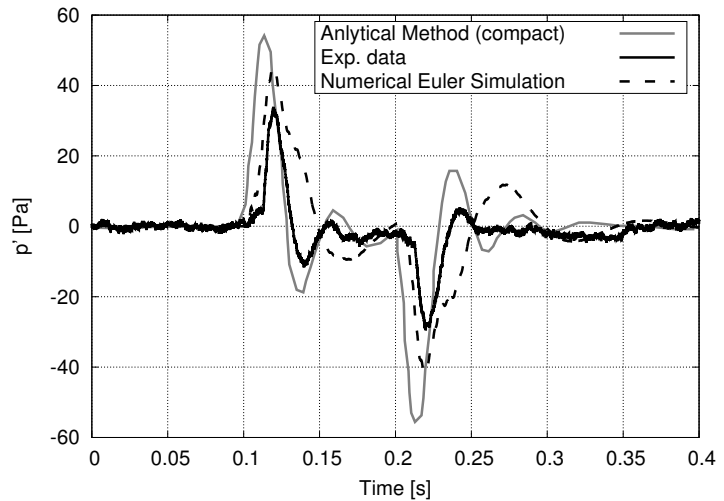

(a) Pressure signal measured at the outlet of the EWG subsonic test case

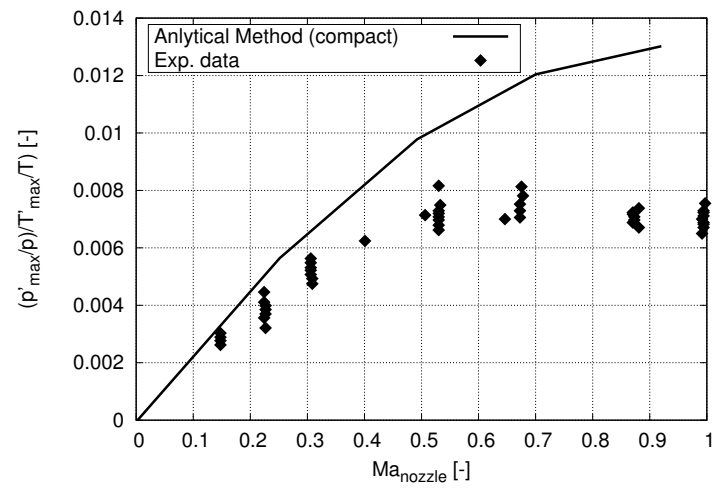

(b) Evolution of the noise peak at the outlet of the EWG versus the nozzle Mach number

Figure 4: Results from the numerical and analytical study of Duran et al. [15].

signal measured in the experiment, which calls for more sophisticated simulations such as a $360^{\circ}$ LES to investigate the influence of the viscosity, the wave deformation in the nozzle, as well as other 3-D effects on the generation of indirect noise. Note that based on these results, the operating point with the nozzle throat Mach number $M_{t h}=0.7$ is chosen, since it corresponds to one of the worst predicted cases in the study of Duran et al. [16] (Figure 4(b)) and where the experimental data levels off instead of continuously increasing.

\section{III.1. The baseline flow simulation}

In this section the Large Eddy Simulation (LES) code AVBP is used to compute the EWG subsonic test case. AVBP is an unstructured combustion LES code that solves the compressible 3-D Navier-Stokes equations. Compared with previous methodologies applied to the EWG subsonic test cases, the present analysis relies on LES to understand the underlying phenomena leading to both direct and indirect noise.

Before the introduction of the entropy perturbation, a mean unperturbed flow needs to be computed. The complete domain of the EWG includes a tranquillisation chamber with a disk after the inlet and a honeycomb flow straightener which can not be simulated without a model in LES. Due to the complexity of the flow inside the tranquillisation chamber, the lack of a model to represent the honeycomb and the uncertainty of the upstream acoustic reflection coefficient, it has been chosen to trim the tranquillisation chamber from the numerical domain and to impose a total pressure boundary condition at the inlet of the domain to ensure an acoustic reflection coefficient close to -1 (due to the sudden expansion of the tranquillisation chamber). The numerical domain of the EWG experiment considered for this study is shown in Figure 5. The resolution of the numerical grid gives values of $Y^{+}$smaller than 35 (maximal value localized in the convergent section - i.e. Figure 6) and a non slip condition is used at walls. The corresponding numerical set-up of the simulation is summarized in Table 2.

Some variables given in the experiment allow to verify if the operating point of the LES is the same as the test case computed. Those variables are summarized in Table 3.

Based on the reported $\mathrm{Y}^{+}$, the resolution of the grid is found to be insufficient to compute the pressure losses properly. Hence, the outlet pressure was increased to match the operating point of the experiment. The mass flow rate was imposed in a first simulation to ensure the same value as in the experiment and the total pressure at the inlet boundary condition was computed and then imposed as a new boundary condition. Imposing pressure rather than the velocity (or the mass flow rate) allows the acoustic boundary condition 


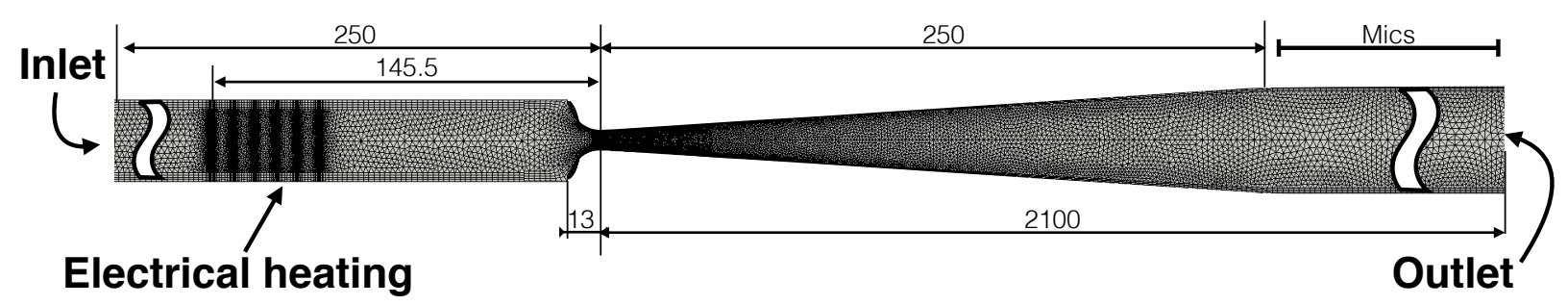

Figure 5: Numerical grid of the EWG (all distances in $\mathrm{mm}$ ).
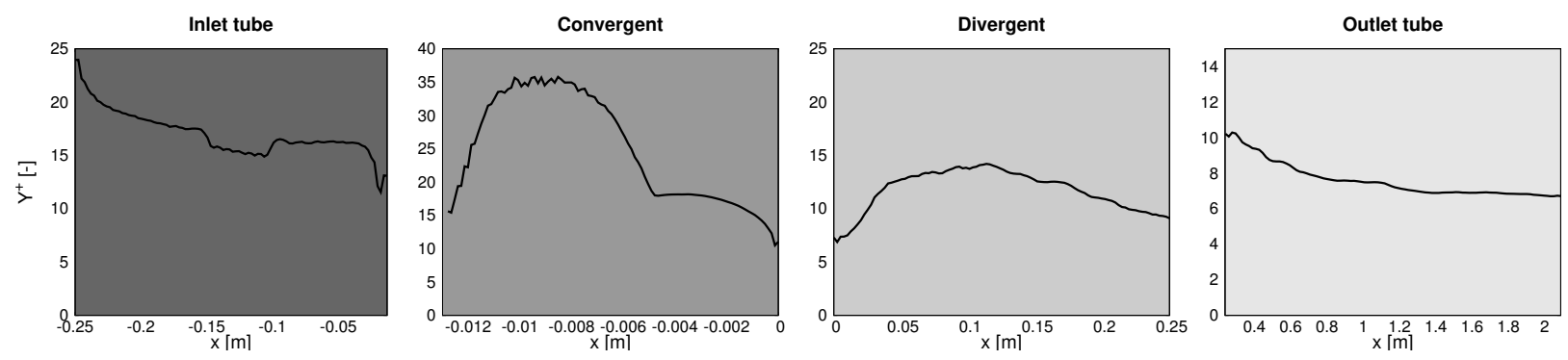

Figure 6: Azimuthal average of wall $\mathrm{Y}^{+}$.

\section{Boundary conditions}

\begin{tabular}{|l|l|}
\hline \hline Inlet & $\begin{array}{l}\text { Partially reflecting }\left(K=1000 \mathrm{~s}^{-1}\right) \text { NSCBC Total pressure, total temperature } \\
\text { and mass fraction imposition } \\
\text { Outlet }\end{array}$ \\
Walls & $\begin{array}{l}\text { Partially reflecting }\left(K=160 \mathrm{~s}^{-1}\right) \text { NSCBC Pressure imposition } \\
\text { Non slip adiabatic }\end{array}$ \\
\hline \multicolumn{2}{|c|}{ Numerical parameters } \\
\hline \hline Governing equations & Navier-Stokes \\
Numerical scheme & TTGC \\
LES model & WALE \\
CFL & 0.7 \\
\hline \multicolumn{2}{|c|}{ Mesh } \\
\hline \hline Hybrid & Four prisms layers and tetrahedra \\
Number of cells & $6.1 \mathrm{M}$ \\
Number of nodes & $1.5 \mathrm{M}$ \\
\hline
\end{tabular}

Table 2: Numerical set-up of the simulations.

to be treated differently, setting the reflection coefficient lower than zero. The nozzle Mach number of the simulation is computed using the same method as in the experiment (i.e. Knobloch et al. [11]). The bulk viscosity in the upstream duct was computed using the total pressure, mass flow rate and the tube cross section (as for the experimental value).

\section{III.2. The entropy forced simulation}

From the unperturbed baseline flow computed in §III.1, entropy fluctuations are introduced in the LES domain by the introduction of an energy source term. In this section a generic model to represent the heating module of the EWG is proposed and used to make a parametric study centred with different shapes of energy deposition. Then the influence of the inlet boundary condition will be addressed and compared with the 


\begin{tabular}{|l|c|c|}
\hline \multicolumn{1}{|c|}{ Parameter } & Experimental value & LES value \\
\hline \hline Mass flow rate & $37 \mathrm{Kg} / \mathrm{s}$ & $37 \mathrm{Kg} / \mathrm{s}$ \\
Nozzle Mach number & 0.7 & 0.72 \\
Bulk velocity (upstream of & $11.39 \mathrm{~m} / \mathrm{s}$ & $11.35 \mathrm{~m} / \mathrm{s}$ \\
the nozzle) & & \\
Pressure settling chamber & $105640 \mathrm{~Pa}$ & $107870 \mathrm{~Pa}$ \\
Pressure nozzle & $68650 \mathrm{~Pa}$ & $68890 \mathrm{~Pa}$ \\
\hline
\end{tabular}

Table 3: Comparison of parameters of the unperturbed flow between the numerical simulation and the experiment.

work of Duran et al. [15].

\section{III.2.1. Modelling of the heating device}

The heating device of the EWG is composed of six modules of electric resistances (a picture of one module is shown in Figure 7), separated from each other by $8 \mathrm{~mm}$. The most upstream heating module is located at $x=-145.5 \mathrm{~mm}$ from the nozzle throat. A gap of $1.8 \mathrm{~mm}$ separates the heating resistances from the duct wall to prevent overheating and fusing of the wires. This implies that only a part of the boundary layer is heated, an effect which has to be accounted for in the LES. Different authors have proposed a model to

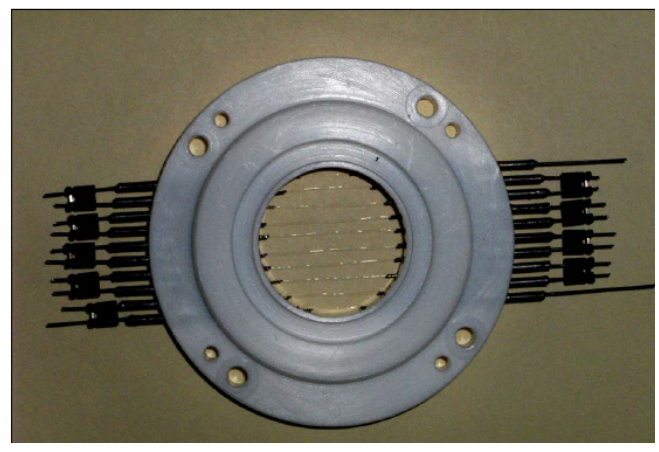

Figure 7: Picture of one heating resistances module.

describe the ignition sequence of this experiment $[13,17,19]$. The model to account for the heating modules consists in the introduction of a volumetric power source term in the energy transportation equation. This source term $\stackrel{\circ}{Q}(x, t)$ is usually computed as the product of one temporal function $\xi(t)$ and a spatial function $\phi(x)$. In order to take into account the gap between the heating wires and the duct wall, another function $\varphi(r)$ is introduced. Furthermore, in this particular experimental test case, each heating module is activated one after the other with a delay corresponding to the convective time of the flow. Hence, the model to describe the heating device proposed in this paper corresponds to Eq.(2):

$$
\begin{gathered}
\stackrel{o}{Q}(x, r, t)=\frac{E_{0}}{n_{\text {rings }}} \sum_{n=1}^{n_{\text {rings }}} \frac{\phi(x) \cdot \varphi(y, z) \cdot \xi(t)}{\iiint_{-\infty}^{\infty} \phi(x) \cdot \varphi(y, z) d V \int_{0}^{\infty} \xi(t) d t} \\
\phi(x)=\frac{1}{2}\left[1+\tanh \left(\frac{x-x_{n}+l_{\text {ring }} / 2}{d}\right) \tanh \left(-\frac{x-x_{n}-l_{\text {ring }} / 2}{d}\right)\right] \\
\xi(t)= \begin{cases}0 & \text { if } t<t_{n} \\
1-\exp \left(-\frac{t-t_{n}}{\tau_{1}}\right) & \text { if } t \in\left[t_{n} ; t_{n}+T_{p}\right] \\
\phi\left(t_{n}+T_{p}\right) \exp \left(-\frac{t-t_{n}-T_{p}}{\tau_{2}}\right) & \text { if } t>t_{n}+T_{p}\end{cases}
\end{gathered}
$$




$$
\varphi(r)= \begin{cases}1 & \text { if } r \in\left[0 ; R_{d e p}\right] \\ 0 & \text { if } r>R_{d e p}\end{cases}
$$

where the different parameters of Eq.(2) are represented in Figure 8.
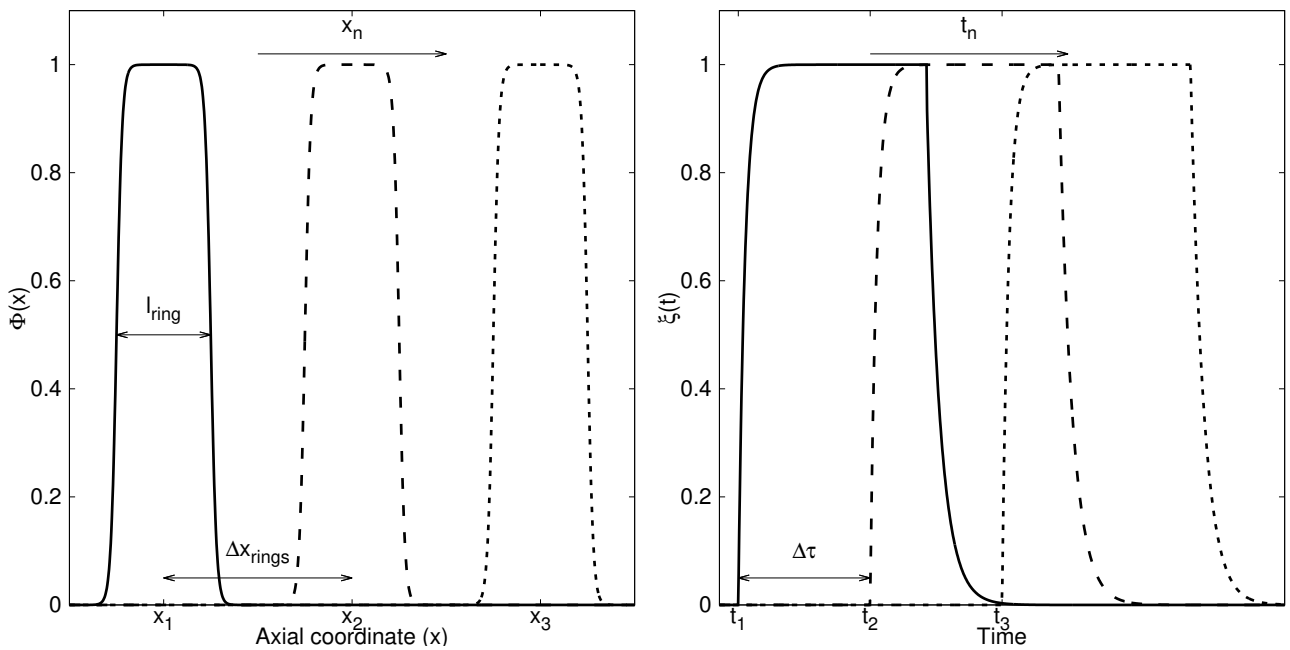

Figure 8: Representation of the spatial (left) and the temporal law (right) of the heating device model, $\phi(x)$ and $\xi(t)$ respectively.

The rest of the parameters involved in the model are: $n_{\text {rings }}$ the number of rings to be activated ( 6 for the computed case), $n$ the index for the $n^{t h}$ ring, $E_{0}$ the total energy to be distributed in time and space, $R_{d e p}$ the radius of deposition, $d$ the characteristic slope of the heating device and $\tau_{1}$ and $\tau_{2}$ the relaxation times of $\xi(t)$.

This model of energy deposition is generic, being able to introduce different energy distributions in both time and space. For instance, this model can reproduce (1) the block model of Leyko et al. [13] and Duran et al. [16] where all the energy was deposited into only one region, and (2) the model of Lourier et al. [19] where the energy is distributed in six different heating wires, each zone being activated at a different instant (the delay being based on the convective time of the mean flow).

In the experiment, once the heating device is activated, a hot spot is convected by the flow, and the temperature fluctuation produced by this energy deposition is measured by a vibrometer located at $x_{v i b}=$ $-58.5 \mathrm{~mm}$ from the nozzle throat. The vibrometer measures the temperature along a line of sight (in this case the diameter of the duct). Hence, the temperature measured by this element can be described as a mean temperature over the diameter as:

$$
T_{\text {vib }}=T_{\text {mean }}=\frac{1}{2 R} \int_{y=-R}^{R} T(y) d y
$$

A relation between the energy deposited by the model and the temperature must be found to compute the energy needed to obtain the temperature fluctuation measured by the vibrometer. The complete energy balance for a flow without chemical reactions is written as:

$$
\rho \frac{D h}{D t}=\frac{D P}{D t}+\frac{\partial^{2} \lambda T}{\partial x_{i}^{2}}+\tau_{i j} \frac{\partial u_{i}}{x_{j}}+\stackrel{o}{Q}
$$

where $h$ is the specific enthalpy, $\rho$ the density, $P$ the pressure, $T$ the temperature, $u_{i}$ the different components of the velocity, $\lambda$ the conductivity, $\tau_{i j}$ the viscous tensor and $\stackrel{o}{Q}$ a volumetric source term. 
To find a relation between the energy deposition and the temperature, a simplified axi-symmetric domain is considered (Figure 9, the mean flow is assumed to be $\vec{U}=U_{x}(y, z) \vec{x}$ ) and some assumptions are used: an established regime $(\partial / \partial t=0)$ without viscous losses $\left(\tau_{i j}=0\right)$ is considered, along with adiabatic walls $\left(\partial T /\left.\partial \vec{n}\right|_{\text {wall }}=0\right)$ and small temperature fluctuations $\left(c_{p} \approx\right.$ constant and $\rho \approx$ constant $)$.

With these assumptions, the energy balance can be recasted as:

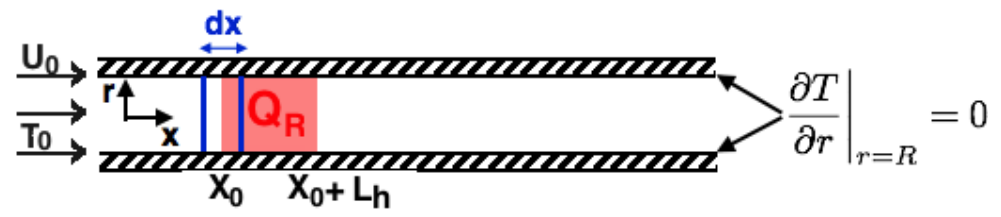

Figure 9: Simplified domain: Cylindrical duct with adiabatic walls.

$$
\rho U_{x} c_{p} \frac{\partial T}{\partial x}=\lambda \frac{\partial^{2} T}{\partial x_{i}^{2}}+\stackrel{o}{Q}
$$

Integrating this relation over a limited volume and introducing the bulk velocity and temperature as new variables

$$
U_{\text {bulk }}=\frac{\iint U_{x}(y, z) d y d z}{A} \quad ; \quad T_{\text {bulk }}(x)=\frac{\iint U_{x}(y, z) T(x, y, z) d y d z}{A U_{b u l k}}
$$

with $A$ the tube cross-section.

The integral of the volumetric source term introduced by the energy model (once all the rings are activated and the experimental temperature plateau is reached $-t=t_{0}+T_{p}$ ):

$$
\iiint \stackrel{o}{Q}\left(x, y, z, t_{0}+T_{p}\right) d V=\frac{E_{0}}{\int_{0}^{t_{0}+T_{p}} \xi(t) d t}
$$

an estimate of the energy to be introduced in the simulation can be written as:

$$
E_{0}=\stackrel{o}{m} c_{p}\left(T_{b u l k}\left(x_{v i b}\right)-T_{b u l k}\left(x_{i n}\right)\right)\left[T_{p}+\left(\tau_{2}-\tau_{1}\right)\left(1-\exp \left(-\frac{T_{p}}{\tau_{1}}\right)\right)\right]
$$

The value for $E_{0}$ computed is $14.2543 \mathrm{~J}$, with $\Delta T_{\text {bulk }}=13.4 \mathrm{~K}$ (where $\Delta T_{\text {bulk }} \neq \Delta T_{\text {mean }}$ by definition) $c_{p}=1004 J . \mathrm{Kg}^{-1} . K^{-1}, T_{p}=0.1 \mathrm{~s}, \tau_{1}=3.5 \mathrm{~ms}$ and $\tau_{2}=7 \mathrm{~ms}$. This estimate of the energy assumes that the bulk temperature is equal to the mean temperature, which in the particular case of a 1D flow is true (not the case of the LES).

In order to evaluate the difference between the bulk and mean temperature profiles, a LES simulating only the duct upstream of the nozzle is computed using the analytical value obtained for the deposited energy $E_{0}$. Figure 10 shows the fluctuation of bulk and mean temperature extracted from this numerical simulation compared with the experimental mean temperature at the vibrometer position. The analytical model is very accurate, the bulk temperature of the simulation collapses with the experimental mean temperature value. Nevertheless, the deposited energy must be corrected to match the mean temperature of the LES with the experimental temperature signal. The correction in energy is computed linearly using the obtained profiles, and the computed value yielding $E_{0}=16.24 \mathrm{~J}$. 4Three different forms of deposition are studied thereafter to analyse the influence of the generation of the hot streak in the generation of entropy noise:

Block deposition : Proposed by Leyko et al. [13]. The energy is deposited over a unique cylinder that contains the six heating wire modules, all rings activated at the same time. The only difference with Leyko et al.'s model is that the volume of deposition is restrained by a radius $R_{d e p}=13.2 \mathrm{~mm}$.

Delayed wide rings: The energy is spread into six cylinders of length $l_{\text {ring }}=7 \mathrm{~mm}$, and a time delay of activation between each cylinder is introduced. 


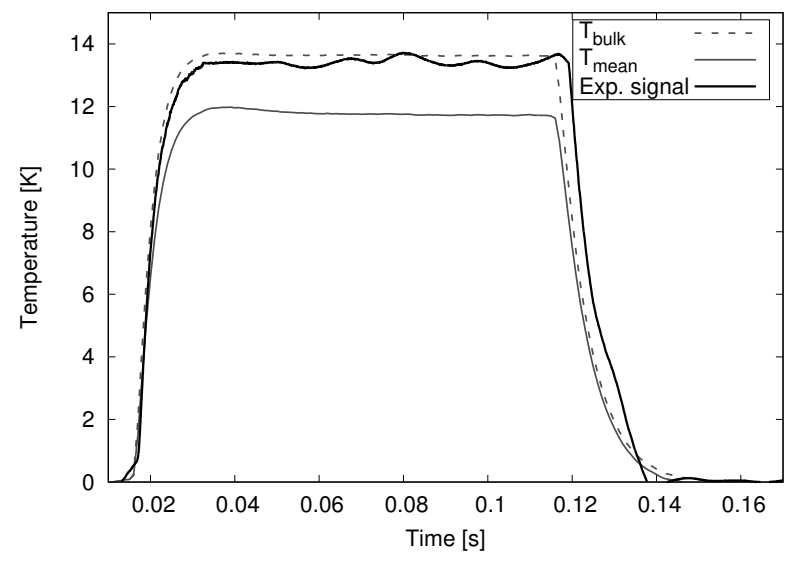

Figure 10: Upstream duct: Bulk temperature and mean temperature of the LES compared with the experimental measurement at vibrometer position $\left(x_{v i b}=-58.5 \mathrm{~mm}\right)$.

Delayed fine rings: The energy is spread into six cylinders of length $l_{\text {ring }}=1 \mathrm{~mm}$, and a time delay of activation between each cylinder is introduced.

According to Eq.(2) the values of the different parameters of the deposition model for the three different test cases are listed in Table 4.

\begin{tabular}{|l|c|c|c|}
\hline Parameter & Block deposition & Delayed wide rings & Delayed fine rings \\
\hline \hline$n_{\text {rings }}$ & 1 & 6 & 6 \\
$E_{0}$ & $14.2543 \mathrm{~J}$ & $14.2543 \mathrm{~J}$ & $14.2543 \mathrm{~J}$ \\
$x_{0}$ & $-125.5 \mathrm{~mm}$ & $-145.5 \mathrm{~mm}$ & $-145.5 \mathrm{~mm}$ \\
$\Delta x_{\text {rings }}$ & $0 \mathrm{~mm}$ & $8 \mathrm{~mm}$ & $8 \mathrm{~mm}$ \\
$l_{\text {ring }}$ & $40 \mathrm{~mm}$ & $7 \mathrm{~mm}$ & $1 \mathrm{~mm}$ \\
$R_{\text {dep }}$ & $13.2 \mathrm{~mm}$ & $13.2 \mathrm{~mm}$ & $13.2 \mathrm{~mm}$ \\
$d$ & $1 \mu \mathrm{m}$ & $1 \mu \mathrm{m}$ & $1 \mu \mathrm{m}$ \\
$t_{0}$ & $0.0 \mathrm{~s}$ & $0.0 \mathrm{~s}$ & $0.0 \mathrm{~s}$ \\
$\Delta \tau$ & $0 \mathrm{~s}$ & $0.702 \mathrm{~ms}$ & $0.702 \mathrm{~ms}$ \\
$T_{p}$ & $0.1 \mathrm{~s}$ & $0.1 \mathrm{~s}$ & $0.1 \mathrm{~s}$ \\
$\tau_{1}$ & $3.5 \mathrm{~ms}$ & $3.5 \mathrm{~ms}$ & $3.5 \mathrm{~ms}$ \\
$\tau_{2}$ & $7 \mathrm{~ms}$ & $7 \mathrm{~ms}$ & $7 \mathrm{~ms}$ \\
\hline
\end{tabular}

Table 4: List of parameters for each deposition model test case.

A transverse cut near the EWG heating device location is shown in Figure 11. The volumetric power deposited in the domain for the three deposition studied test cases is represented at time $t=200 \mathrm{~ms}$ from the triggering of the pulse (end of the deposition). This figure illustrates how the energy is distributed in the different rings. Note that when the deposition volume is smaller, more energy per unit of volume is introduced, leading to a more brutal and shorter heating, which may impact both the direct noise and entropy spot generation.

The first instants of the energy deposition are compared for the different models. The first $20 \mathrm{~ms}$ of energy deposition are shown in Figure 12, where the mean temperature and pressure traces are compared with the experimental values. The block deposition model induces a time delay of $\approx 3 \mathrm{~ms}$ in the temperature and pressure signals. This delay is due to the fact that the first temperature front seen by the vibrometer comes from the most downstream heating ring. Whereas for the delayed models, the activation delay is computed 


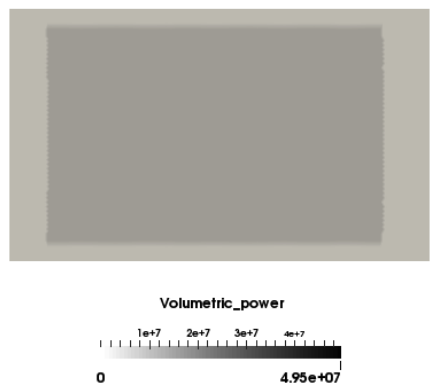

(a) Bloc deposition model

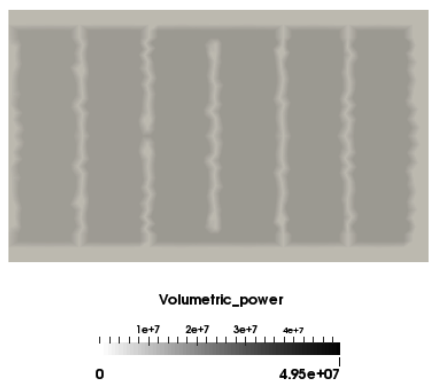

(b) Delayed wide rings model

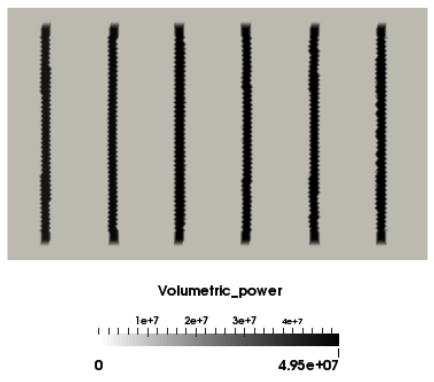

(c) Delayed fine rings model

Figure 11: Volumetric power deposited in the numerical simulation for the three different deposition models.

to be equal to the convection velocity of the flow, the first temperature front seen by the vibrometer comes from the furthest away ring. Hence, taking the mean values from Bake et al. [9], the bulk velocity in the upstream tube $U_{\text {bulk }} \approx 11.4 \mathrm{~m} / \mathrm{s}$ and total length of the heating device $l_{h d}=40 \mathrm{~mm}$, results effectively in a time delay of $\approx 3.5 \mathrm{~ms}$.

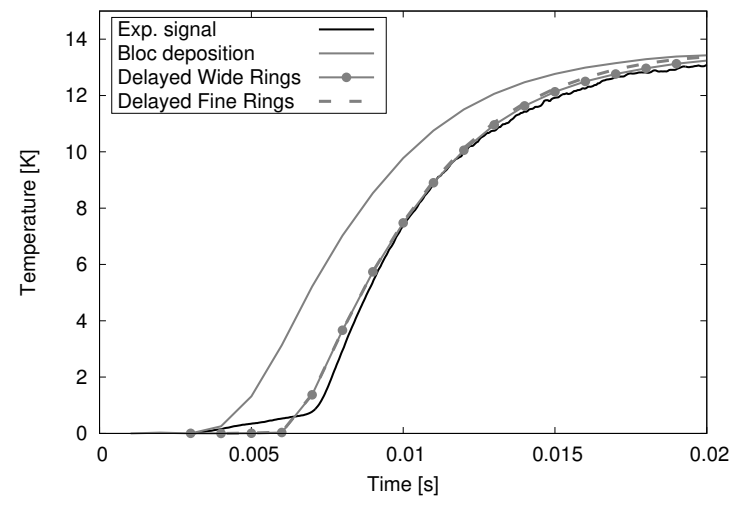

(a) Mean temperature traces at vibrometer position $\left(x_{v i b}=-58.5 \mathrm{~mm}\right)$

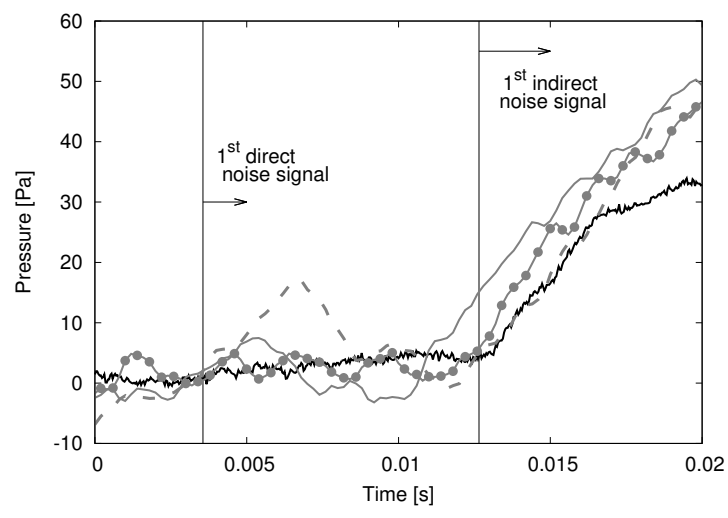

(b) Pressure traces at microphone 4 position $\left(x_{\text {mic } 4}=\right.$ $1150.5 \mathrm{~mm})$

Figure 12: Zoom over the first instants of energy deposition.

According to the work of Lourier et al. [19] concerning the time delay of different noise sources (direct or indirect noise), the first direct noise signal (noise produced by the heating of the heating device) starts at $\approx 4 \mathrm{~ms}$ from the triggering of the energy deposition. The first indirect noise signal (due to the acceleration of the hot spot through the nozzle) arrives at $\approx 12.5 \mathrm{~ms}$. As expected, direct noise generated by the block deposition model and the delayed model with wide rings is less than the delayed model with fine rings. The same energy is deposited for all the test cases, the difference laying in the deposited volume. The delayed model with wide rings allows steeper gradients of temperature, generating at the same time more direct noise. Finally, the complete pressure trace given by the delayed fine ring model is shown in Figure 13 and compared with the work of Duran et al. [15], where a good agreement is obtained between the numerical simulation and the experiment. Nevertheless, the peak pressure is still overestimated and found to be in agreement with the results of Duran et al. Direct noise is overestimated in comparison with the experimental value by the LES, but the shape of the signal is in better agreement with the experimental one. Direct noise and indirect noise first fronts are in agreement with Lourier's study. Finally, the application of the High-Pass (HP) filter discussed in §II (i.e. Figure 3) over the pressure signal is shown in Figure 14. The spectrum of the pressure signal at the fourth microphone and the spectrum of the filtered pressure signal (applying the microphones transfer function) is depicted in Figure 14(a) . The microphones clearly damp 
the frequencies lower than $\approx 10 \mathrm{~Hz}$, which is the characteristic frequency of the hot slug (time duration of the pulse $T_{p}=0.1 \mathrm{~s}$ ). The temporal filtered pressure signal of the LES and Duran et al. [15] numerical simulation is showed in Figure 14(b). The filter has an effect from the first indirect noise front of the LES, leaving the first instants of the direct noise signal unaffected and the peak pressure of the LES matches the experimental pressure peak. Duran's Euler simulation has been shifted by the filter and it is not possible to identify the contribution of direct or indirect noise in the signal.

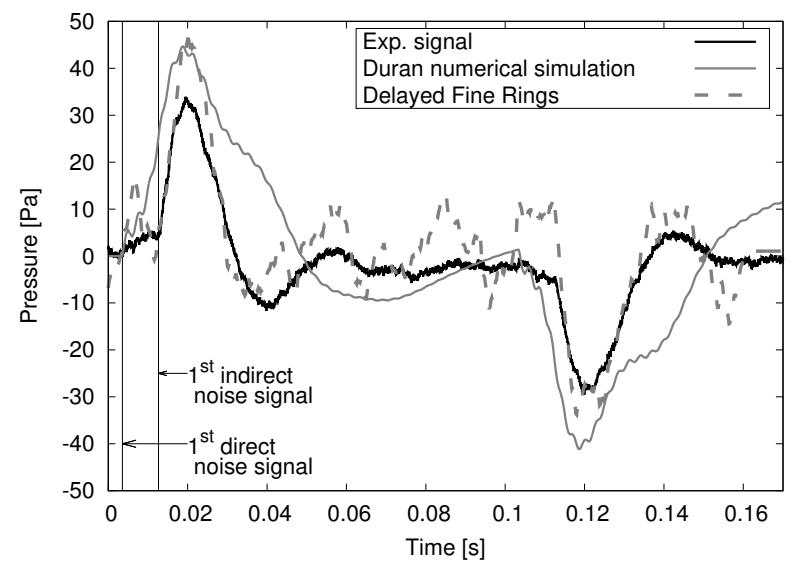

Figure 13: Pressure traces at the fourth microphone position $\left(x_{m i c 4}=1150.5 \mathrm{~mm}\right)$.

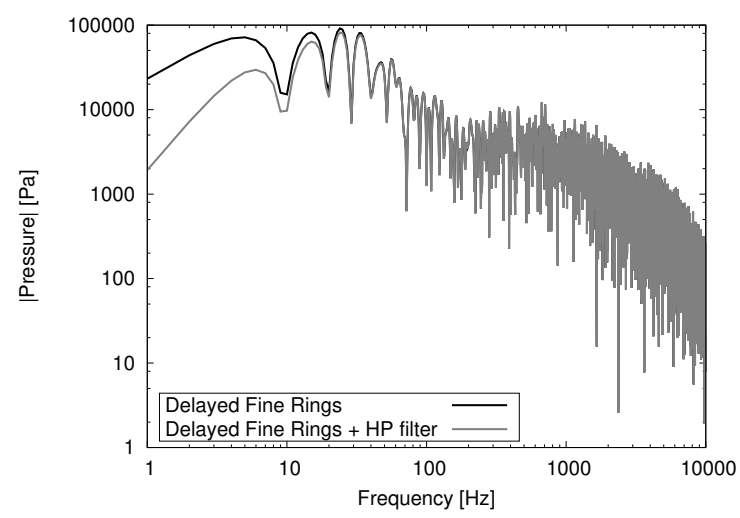

(a) Modulus of the Discrete Fourier Transform of the pressure signal of the LES (filtered and not filtered).

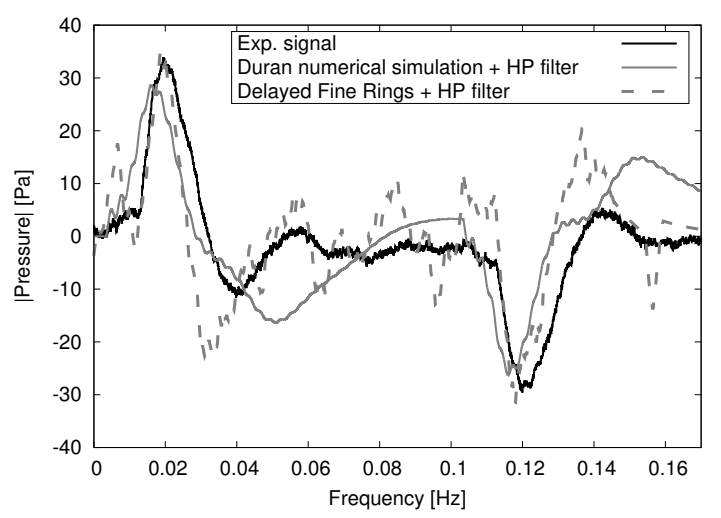

(b) LES and Duran et al. [15] pressure signals filtered by the transfer function of the microphones compared with the experimental signal

Figure 14: Influence of the filtering due to the microphones on the pressure signal of the LES.

A good agreement between the filtered pressure signal of the LES (when applying the delayed fine ring deposition model and the filtering due to the microphones) and the experimental measurement at the fourth microphone is observed. Nevertheless, two remarks can be made. First, an overestimation of direct noise is found in the LES if compared to the experimental pressure value. Second, the LES pressure signal is not completely overlapped with the experimental signal. Both effects may be due to the resolution of the numerical grid. The mesh in the deposition zone is very fine, and is stretched rapidly which can generate some numerical noise. The resolution near the wall is poor, making the spot to be convected potentially at the wrong velocity near walls, which may generate some dispersion. Finally, some numerical diffusion of the hot slug can emerge between the generation of the slug and the convection through the nozzle throat.

The study proposed here is a full 360 degree LES simulation. In order to evaluate the $3 \mathrm{D}$ effects on the entropy spot and its deformation through the nozzle throat, the temperature gradient is computed to 
visualize the shapes of the entropy fronts. Figure 15 shows the norm of the temperature gradient of the forced simulation divided by the mean temperature of the unperturbed flow $\left(\|\nabla T\| / \bar{T}_{0}\right)$, this magnitude allows to track the position of the entropy front. At the first instant represented in this figure, the entropy spot is located in the upstream duct, one can see that the temperature front is not flat and further more has lobes near the wall. This is caused by the velocity profile and the constant heating in the radial direction. At the second instant, the entropy spot is located inside the nozzle diffuser and its front shape completely distorted. In the last instant, the front is already in the outlet duct and a "stationary state" has been reached in the upstream duct. In Figure 16, an azimuthal average of the reduced temperature defined as the ratio of the temperature of the forced simulation minus the mean temperature of the non forced flow over the mean temperature of the non forced flow $\left(T_{\text {dimless }}=\left(T-\bar{T}_{0}\right) / \bar{T}_{0}\right)$ is computed. The position of the heating device is represented by the shaded region, whereas the vertical lines represent the separation between the different components of the geometry: inlet duct, convergent and diffuser of the nozzle and outlet duct. This figure shows that the heating inside the heating device region is linear. As the walls are adiabatic the convection of the hot spot towards the the nozzle looks like a plateau. When the mean state is reached the convergent and diffuser parts do not evolve much. Furthermore, the convergent region seems to heat the fluid instead of cooling it and the temperature remains more or less constant in the diffuser. Finally, an attenuation of the entropy spot is seen in the outlet duct due to shear dispersion arising from the velocity profile as described by Morgans et al. [22].
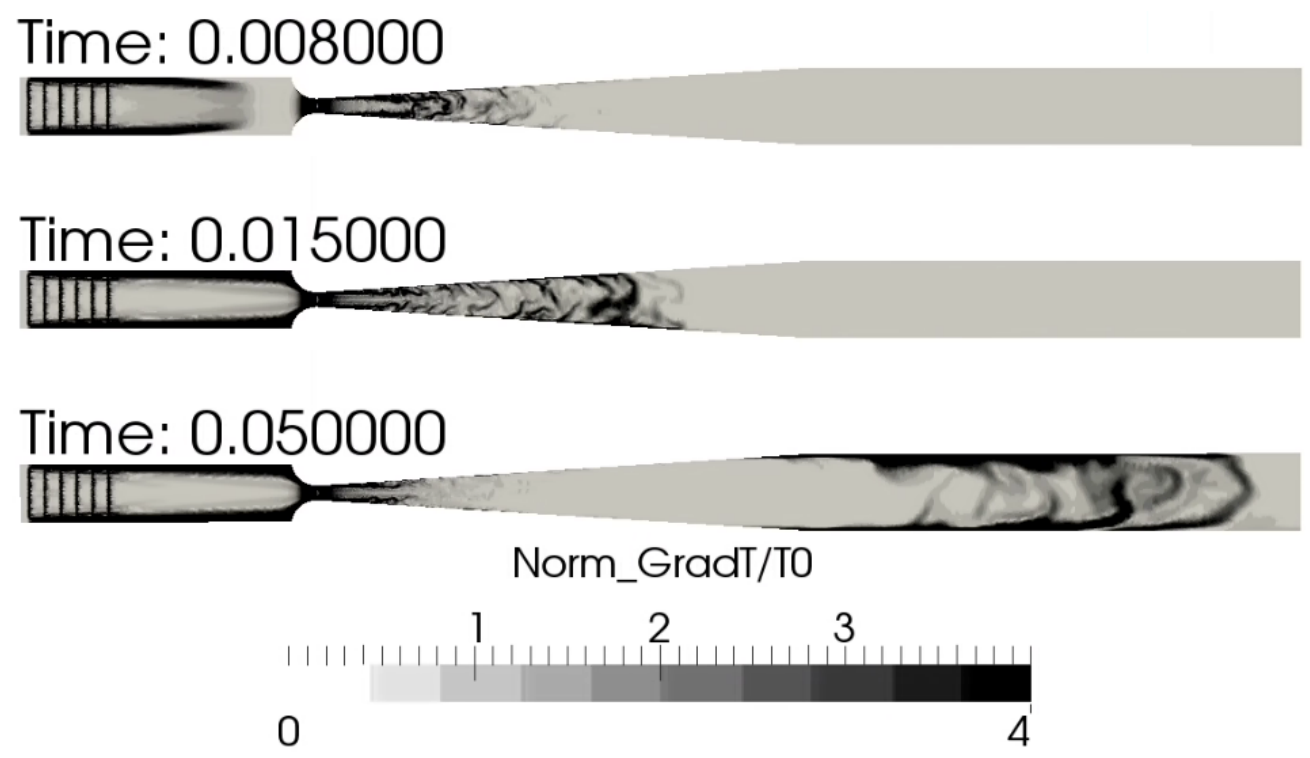

Figure 15: Norm of the temperature gradient of the forced flow divided by the mean temperature of the non forced flow $\left(\|\nabla T\| / \bar{T}_{0}\right)$. Only a part of the EWG geometry is represented $(x \in[-0.15: 0.5])$.

\section{III.2.2. Inlfuence of the inlet acoustic boudary condition}

In this section the influence of acoustic boundary conditions will be addressed. The impedance of the inlet of the EWG is unknown. Leyko et al. [13] studied a supersonic operating point with a shock inside the diffuser. In its work Leyko proposes that since the inlet duct of the EWG is connected to a large cavity, the inlet reflection coefficient must be close to -1 . Nevertheless, for a supersonic case (that was studied in this work) the inlet boundary condition is irrelevant and setting $R_{i n}=-1$ or 0 gave very similar results. Duran et al. [15] proposed to take into account the reflection coefficient from the inlet of the settling chamber and approached it by the relation $R_{i n}=\left(1-M_{i n}\right) /\left(1+M_{i n}\right)$, which gave a reflection coefficient close to $R_{i n}=1$. For the subsonic case studied by Duran, setting $R_{i n}=0$ or 1 changes drastically the shape and pressure peaks of the signal. Therefore, an uncertainty over the value of the inlet impedance. In this section a LES computation where the inlet boundary condition is changed to impose a mass flow rate rather than a total pressure (as done in the precedent section). Physically, the mass flow rate will be the same in both simulations, but the acoustics are treated differently, in this case setting $R_{\text {in }}$ greater than 0 (partially 

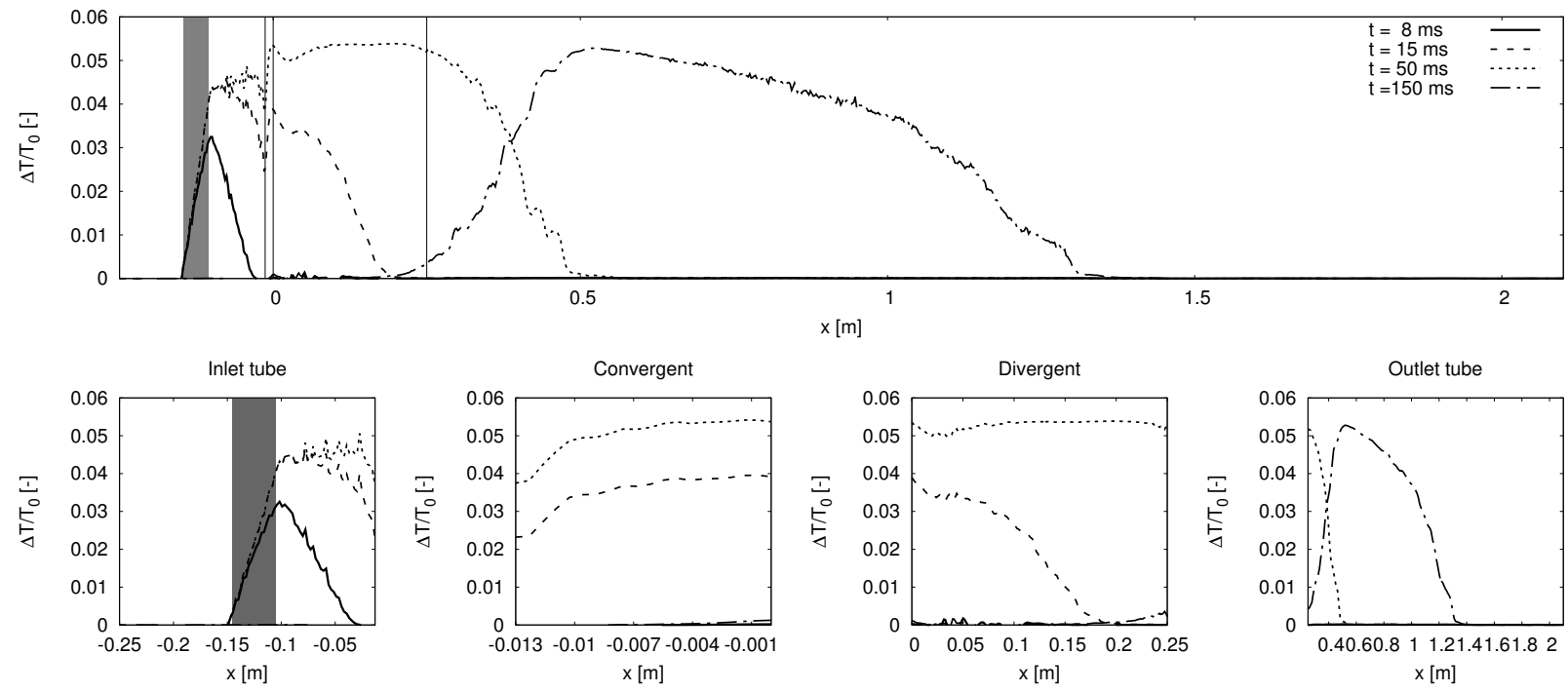

Figure 16: Azimuthal average of the dimensionless temperature defined as $T_{\text {dimless }}=\left(T-\bar{T}_{0}\right) / \bar{T}_{0}$. Shaded region: Heating Device localtion. Vertical lines: separation between the inlet duct, the convertent and diffuser of the nozzle and the outlet duct.

reflecting). The same mesh and numerical set-up are used, only the delayed model with fine rings will be used to represent the heating device, Table 5 recalls the boundary conditions used for this simulation.

\begin{tabular}{|l|l|}
\hline Inlet & Partially reflecting $\left(K=1000 \mathrm{~s}^{-1}\right)$ NSCBC Mass flow rate and temperature \\
Outlet & Partially reflecting $\left(K=160 \mathrm{~s}^{-1}\right)$ NSCBC Pressure \\
Walls & Non slip adiabatic \\
\hline
\end{tabular}

Table 5: Boundary conditions for the simluation with $R_{\text {in }} \approx 1$.

Pressure traces are extracted from the simulation at the inlet duct to compare the influence of the inlet boundary condition. Then analytic model proposed by Druan et al. [15] is used to compare the results of the LES with the analytic theory. In its analytic model, Duran proposed to model the heating device as compact, in which the acoustic and entropy waves are described as follows:

$$
\begin{aligned}
\sigma_{h} & =\xi(t) \frac{T^{\prime}}{\bar{T}} \\
P_{h}^{+} & =\frac{M_{1}}{2\left(M_{1}+1\right)} \xi(t) \frac{T^{\prime}}{\bar{T}} \\
P_{h}^{-} & =\frac{M_{1}}{2\left(1-M_{1}\right)} \xi(t) \frac{T^{\prime}}{\bar{T}} \\
P_{h} & ==P_{h}^{+}+R_{i n} P_{h}^{-}
\end{aligned}
$$

with $\xi(t)$ the temporal function to model the heating device proposed in $\S I I I .2 .1, T^{\prime}$ the temperature fluctuation (in this case $T^{\prime}=13.5 \mathrm{~K}$ ), $\bar{T}$ the mean temperature and $M_{1}$ the upstream mean Mach number. For the modelling of the heating device, in this case six compact rings are used and activated one after the other to take into account the ignition sequence of the heating device. Then the acoustic and entropic transfer functions of the nozzle are obtained by the solution of the Linearised Euler Equations (following the work of Duran and Moreau [8]). Finally, the pressure inside the inlet duct can be expressed as the addition of the acoustic waves:

$$
P_{\text {inlet duct }}(x)=\frac{\gamma P_{a t m}}{2}\left(P_{h}+A_{1}^{+}-A_{1}^{-}\right)
$$


where $A_{1}^{+}$and $A_{1}^{-}$are the acoustic upstream travelling waves resulting from the solution of the linear system constructed in Section $C$ of Duran et al. [15]. Finally, the reflection coefficients for the analytic model are imposed by the analytic expression for NSCBC boundary conditions (i.e. Selle et al. [21]):

$$
\begin{aligned}
R_{\text {in }} & =\frac{ \pm 1}{1+i \frac{\omega}{1000}} \\
R_{\text {out }} & =\frac{-1}{1+i \frac{\omega}{1000}}
\end{aligned}
$$

Figure 17 shows the resulting pressure trace obtained by the analytic model compared to the recorded pressure in the LES for both boundary conditions tested. The analytic model predicts correctly the trend of the pressure signals. When a mass flow rate is imposed $\left(R_{i n}>0\right)$, pressure fluctuations recorded at the vibrometer location are more than two times greater than when a total pressure is imposed, which means that more noise is produced in this case. A time delay is observed between the analytic and the LES signals. Nevertheless, the analytic model allows to have an estimation of the contribution of direct noise and indirect noise registered in each simulation. If $\sigma_{h}$ is set to zero, direct noise will be obtained without the contribution of indirect noise and the other way around. Figure 18 shows the contribution of direct and indirect noise computed by the analytic model. The dominant noise source predicted by the analytical model in the upstream duct for both cases is the direct noise.
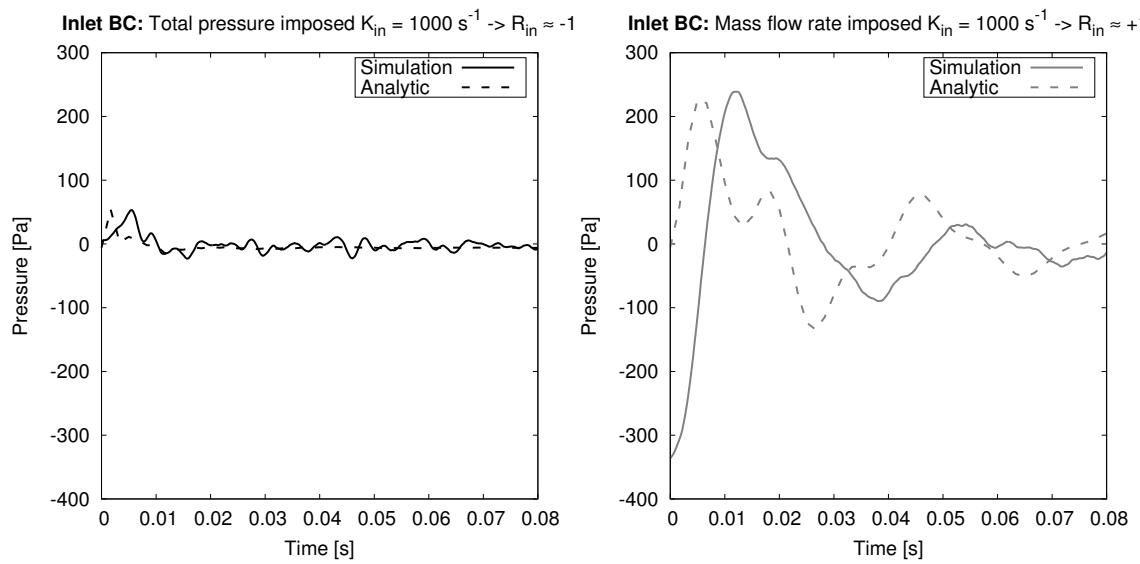

Figure 17: Pressure trace recorded at the vibrometer position $\left(x_{v i b}=-58.5 \mathrm{~mm}\right)$ of the LES compared to the analytic model proposed by Duran et al. [15]
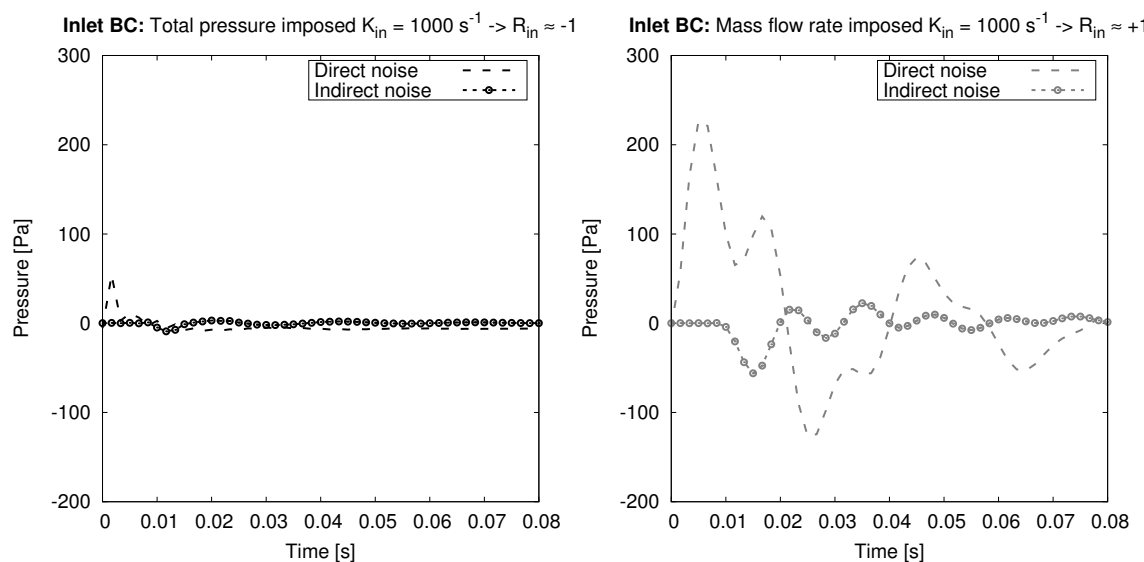

Figure 18: Contribution of direct and indirect noise to pressure recorded at the vibrometer position $\left(x_{v i b}=-58.5 \mathrm{~mm}\right)$ obtained by the analytic model proposed by Duran et al. [15] 
Finally, Figure 19 regroups the resulting pressure traces of both LES simulations and its analytical modelling to obtain direct and indirect noise contribution and compare them to the experimental pressure values. When applying a total pressure boundary condition $\left(R_{\text {in }}\right.$ close to -1$)$, the shape and amplitude of the experimental signal are nearly recovered (note that no filtering is applied in this case), and the analytical model indicates that direct and indirect noise have the same level of contribution to the overall pressure signal. Whereas when imposing a mass flow rate, neither the shape nor the amplitude of the experimental signal is recovered. Furthermore, the amount of direct noise generated is one order of magnitude greater than indirect noise. The analytical modelling of this experience allows to have a good agreement when direct noise is predominant but fails when indirect noise contribution starts to be of the same order of magnitude as direct noise. Due to two hard hypothesis concerning the analytical method. The first one that assumes the convection of only plane waves, when it has been shown that for this experiment the entropy wave has strong 3D effects. The second strong hypothesis consists in assuming that the fluctuations of entropy remain constant when the entropy wave passes through the nozzle. In reality, the entropy wave suffers from shear dispersion and the energy of the entropy modes redistributes into higher-order modes as studied by Leyko et al. [23], Duran and Moreau [24], Duran et al. [25].
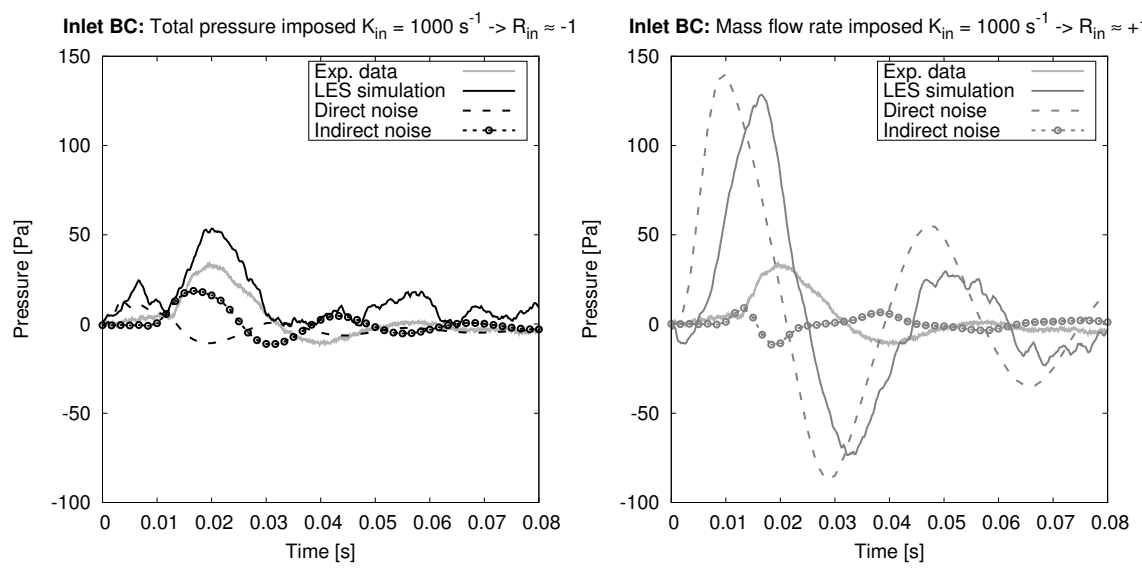

Figure 19: Contribution of direct and indirect noise to pressure recorded at the vibrometer position $\left(x_{v i b}=-58.5 \mathrm{~mm}\right)$ obtained by the analytic model proposed by Duran et al. [15]

\section{Conclusion}

The Entropy Wave Generator (EWG) experiment (described by Bake et al. [9]) has been studied in this paper, focusing on the subsonic operating point. A parametric study concerning the modelling of the heating device and the inlet acoustic boundary conditions has been carried by means of LES and guided by analytical models.

It has been found that it is necessary to take into account the time delay between the activation of the heating modules, as done in the ignition sequence used in the experiment. Three different deposition shapes were studied with the same energy deposited in the domain. The block model deposition (in which all the heating modules are activated at the same time) shows that the LES temperature and pressure signals are delayed $\approx 3 \mathrm{~ms}$ compared with the experimental results. This is due to the ignition sequence, in which the first front seen by the vibrometer comes from the must downstream ring (the nearest to the vibrometer). Then the contribution of the delayed model with a fine representation of the heating rings shows that more direct noise is generated due to the brutal heating of the flow. Nevertheless, the three deposition shapes show very similar results, the differences are only in the time delay and direct noise. Showing that the indirect noise is only dependent on the deposited energy (overall mean temperature fluctuation) and not on the shape of the deposition. Furthermore, the transfer function of the experimental probes has been taken into account obtaining a better result of the LES when comparing to the experiment.

A strong influence of the inlet acoustic boundary condition on the predicted pressure signals and di- 
rect/indirect noise contribution has been found. When considering a mass flow rate or velocity imposed boundary condition, neither the shape, nor the amplitude of the experimental signals are recovered. Furthermore, the contribution of direct noise to the overall pressure signal is one order of magnitude bigger than indirect noise. In this case, the analytical model proposed gives good results when comparing to the experiment. Considering a pressure imposed boundary condition, no dominant noise source (direct or indirect) has been found, both contribute very closely to the overall pressure signal. In this case, when indirect

noise contribution is close to direct noise, the analytical model fails to reproduce the correct amount of pressure. This is explained in the works of Leyko et al. [23], Duran and Moreau [24], Duran et al. [25], by the distribution of entropy fluctuations into higher-order modes due to the non uniform velocity convection of the entropy wave.

A full resolved LES is ongoing to study the effects of the thermal boundary layer in the temperature profile after the generation of the hot streak and its influence in the generation of noise. Furthermore, it will be possible to study the influence of viscous effects on the dissipation of indirect noise for high Mach regimes as suggested by Howe [20] and depicted in Figure 4.

\section{Acknowledgements}

The authors gratefully acknowledge all RECORD (Research on Core Noise Reduction) partners for providing experimental and numeric data for this work. And for the funding from the European Union Seventh Framework Collaborative project RECORD under Grant No. RG66913. The authors also gratefully acknowledge Dr. Friedrich Bake from DLR for all the experimental data and Frédérique DUVINAGE from AllianTech for the complementary informations on transfer functions of the microphones. 


\section{References}

${ }^{1}$ Tsien, H. S., "The transfer functions of rocket nozzles," J. American Rocket Society, Vol. 22, No. 3, 1952, pp. $139-143$.

${ }^{2}$ Marble, F. E. and Candel, S., "Acoustic disturbances from gas nonuniformities convected through a nozzle," J. Sound Vib. , Vol. 55, 1977, pp. 225-243.

${ }^{3}$ Cumpsty, N. A. and Marble, F. E., "The interaction of entropy fluctuations with turbine blade rows; a mechanism of turbojet engine noise," Proc. R. Soc. Lond. A , Vol. 357, 1977, pp. 323-344.

${ }^{4}$ Huet, M. and Giauque, A., "A nonlinear model for indirect combustion noise through a compact nozzle," J. Fluid Mech. , Vol. 733, 2013, pp. 268-301.

${ }^{5}$ Moase, W., Brear, M., and Manzie, C., "The forced response of choked nozzles and supersonic diffusers," Journal of Fluid Mechanics, Vol. 585, 2007, pp. 281-304.

${ }^{6}$ Stow, S., Dowling, A., and Hynes, T., "Reflection of circumferential modes in a choked nozzle," Journal of Fluid Mechanics, Vol. 467, 2002, pp. 215-239.

${ }^{7}$ Goh, C. S. and Morgans, A. S., "Phase prediction of the response of choked nozzles to entropy and acoustic disturbances," Journal of Sound and Vibration, June 2011, pp. 1-15.

${ }^{8}$ Duran, I. and Moreau, S., "Solution of the quasi one-dimensional linearized Euler equations using flow invariants and the Magnus expansion," Journal of Fluid Mechanics, Vol. 723, May 2013, pp. 190-231.

${ }^{9}$ Bake, F., Richter, C., Muhlbauer, B., Kings, N., I.Rohle, F.Thiele, and B.Noll, "The Entropy Wave Generator (EWG): a reference case on entropy noise," J. Sound Vib. , 2009, pp. 574-598.

${ }^{10}$ Knobloch, K., Werner, T., and Bake, F., "Noise Generation in Hot Nozzle Flow," ASME Turbo Expo 2015: Turbine Technical Conference and Exposition, No. GT2015-43702, American Society of Mechanical Engineers, 2015.

${ }^{11}$ Knobloch, K., Werner, T., and Bake, F., "Entropy Noise Generation and Reduction in a Heated Nozzle Flow," 21st AIAA/CEAS Aeroacoustics Conference, No. AIAA 2015-2818, 2015, p. 2818.

${ }^{12}$ Ullrich, W., Sattelmayer, T., Kings, N., and Bake, F., "Numerical Investigation of Indirect Noise Generation by Accelerated Vorticity," 21st AIAA/CEAS Aeroacoustics Conference, No. AIAA 2015-2382, 2015, p. 2382.

${ }^{13}$ Leyko, M., Moreau, S., Nicoud, F., and Poinsot, T., "Numerical and analytical modelling of entropy noise in a supersonic nozzle with a shock," J. Sound Vib. , Vol. 330, No. 16, 1, 2011, pp. 3944-3958.

${ }^{14}$ Schønfeld, T. and Rudgyard, M., "Steady and Unsteady Flows Simulations Using the Hybrid Flow Solver AVBP," AIAA Journal, Vol. 37, No. 11, 1999, pp. 1378-1385.

${ }^{15}$ Duran, I. and Moreau, S., "Analytical and numerical study of the Entropy Wave Generator experiment on indirect combustion noise," 17th AIAA/CEAS Aeroacoustics Conference - AIAA-2011-2829, No. AIAA 2011-2829, Portland, Oregon, 2011.

${ }^{16}$ Duran, I., Moreau, S., and Poinsot, T., "Analytical and numerical study of combustion noise through a subsonic nozzle," AIAA Journal, Vol. 51, No. 1, 2013, pp. 42-52.

${ }^{17}$ Muhlbauer, B., Noll, B., and Aigner, M., "Numerical investigation of the fundamental mechanism for entropy noise generation in aero-engines," Acta Acustica united with Acustica 95, Vol. 95, No. 3, 2009, pp. 470-478.

${ }^{18}$ Ullrich, W., Gikadi, J., Jörg, C., and Sattelmayer, T., "Acoustic-entropy coupling behavior and acoustic scattering properties of a Laval nozzle," 20th AIAA/CEAS Aeroacoustics Conference, No. AIAA 2014-3193, 2014.

${ }^{19}$ Lourier, J. M., Huber, A., Noll, B., and Aigner, M., "Numerical analysis of indirect combustion noise generation within a subsonic nozzle," AIAA Journal, Vol. 52, No. 10, 2014, pp. 2114-2126.

${ }^{20}$ Howe, M. S., "Indirect combustion noise," J. Fluid Mech., Vol. 659, 8 2010, pp. 267-288.

${ }^{21}$ Selle, L., Nicoud, F., and Poinsot, T., "The actual impedance of non-reflecting boundary conditions: implications for the computation of resonators," AIAA Journal , Vol. 42, No. 5, 2004, pp. 958-964.

${ }^{22}$ Morgans, A. S., Goh, C. S., and A., D. J., "The dissipation and shear dispersion of entropy waves in combustor thermoacoustics," Journal of Fluid Mechanics, Vol. 733, 2013, pp. R2.

${ }^{23}$ Leyko, M., Moreau, S., Nicoud, F., and Poinsot, T., "Waves transmission and generation in turbine stages in a combustionnoise framework," 16th AIAA/CEAS AeroAcoustics Conference, 2010.

${ }^{24}$ Duran, I. and Moreau, S., "Study of the attenuation of waves propagating through fixed and rotating turbine blades," 18th AIAA/CEAS Aeroacoustics Conference (33rd AIAA Aeroacoustics Conference), No. AIAA2012-2133 paper, Colorado Springs, USA, June 4-6 2012.

${ }^{25}$ Duran, I., Leyko, M., Moreau, S., Nicoud, F., and Poinsot, T., "Computing combustion noise by combining Large Eddy Simulations with analytical models for the propagation of waves through turbine blades," Comptes Rendus de l'Académie des Sciences - Mécanique, Vol. 341, No. 1-2, January 2013, pp. 131-140. 